\title{
Wentilactone B induces G2/M phase arrest and apoptosis via the Ras/Raf/MAPK signaling pathway in human hepatoma SMMC-7721 cells
}

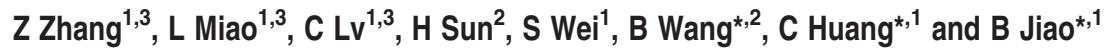

Hepatocellular carcinoma (HCC) is generally acknowledged as the most common primary malignant tumor, and it is known to be resistant to conventional chemotherapy. Wentilactone $B(\mathrm{WB})$, a tetranorditerpenoid derivative extracted from the marine algaederived endophytic fungus Aspergillus wentii EN-48, has been shown to trigger apoptosis and inhibit metastasis in HCC cell lines. However, the mechanisms of its antitumor activity remain to be elucidated. We report here that WB could significantly induce cell cycle arrest at G2 phase and mitochondrial-related apoptosis, accompanying the accumulation of reactive oxygen species (ROS). Additionally, treatment with WB induced phosphorylation of extracellular signal-regulated kinase (ERK), c-Jun N-terminal kinase (JNK), but not p38 MAP kinase. Among the pathway inhibitors examined, only SP600125 (JNK inhibitor) markedly reversed WB-induced apoptosis, and only U0126 (ERK inhibitor) significantly blocked WB-triggered G2 phase arrest. We also found that WB treatment increased both Ras and Raf activation, and transfection of cells with dominant-negative Ras (RasN17) abolished WB-induced apoptosis and G2 phase arrest in SMMC-7721 cells. Furthermore, the results of inverse docking (INVDOCK) analysis suggested that WB could bind to Ras-GTP, and the direct binding affinity was also confirmed by surface plasmon resonance (SPR). Finally, in vivo, WB suppressed tumor growth in mouse xenograft models. Taken together, these results indicate that WB induced G2/M phase arrest and apoptosis in human hepatoma SMMC-7721 cells via the Ras/Raf/ERK and Ras/Raf/JNK signaling pathways, and this agent may be a potentially useful compound for developing anticancer agents for HCC.

Cell Death and Disease (2013) 4, e657; doi:10.1038/cddis.2013.182; published online 6 June 2013

Subject Category: Cancer

Hepatocellular carcinoma (HCC) is considered to be one of the most common causes of cancer-related death based on Cancer Statistics reported in 2011. ${ }^{1-3}$ Although surgical resection and liver transplantation are widely used to control its pathology, there are still no effective therapeutic options available to treat advanced $\mathrm{HCC}$ due to its resistance to chemotherapy and radiotherapy. ${ }^{4}$ Thus, novel therapeutic agents are urgently needed to minimize the incidence and severity of this cancer.

Many cytotoxic agents and/or DNA-damaging agents arrest cell cycling at G1, S or G2/M phase. ${ }^{5}$ Progression from G2 to $M$ phase is regulated by a number of the cyclin family members, in particular cyclin B1 and cdc2. Cyclin B1, together with cyclin A, promotes the G2/M transition. ${ }^{6,7}$ Meanwhile, cdc2 is essential for the G1/S and G2/M phase transitions of the eukaryotic cell cycle. The phosphorylation and dephosphorylation of cdc2 have important regulatory roles in the control of the cell cycle. ${ }^{8}$ Moreover, the phosphatase activity of cdc25C is also implicated in the regulation of the progression of G2/M phase. ${ }^{9}$

Apoptosis, which is characterized by cytoplasmic shrinkage, chromatin condensation and DNA fragmentation, is an active form of cell death that occurs in response to several agents, including anticancer chemotherapeutic drugs. ${ }^{10-12}$ In addition to the caspase family proteins and $\mathrm{Bcl}-2$ family members, some other biomarkers and events could also be considered as the determinants of apoptosis. ${ }^{13}$ Reactive oxygen species (ROS) is the mediator of intracellular signaling cascades. ${ }^{14}$ The abnormal production of the molecule may trigger redox signaling pathways, such as oxidative stress, cell cycle arrest and apoptosis. ${ }^{15}$ In addition, disruption of the mitochondrial transmembrane potential is considered to be one of the apoptotic processes induced by chemotherapeutic drugs. $^{16}$

\footnotetext{
${ }^{1}$ Department of Biochemistry and Molecular Biology, Faculty of Basic Medicine, Second Military Medical University, Shanghai, China and ${ }^{2}$ Key Laboratory of Experimental Marine Biology, Institute of Oceanology, Chinese Academy of Sciences, Qingdao, China

*Corresponding author: C Huang or B Jiao, Department of Biochemistry and Molecular Biology, Faculty of Basic Medicine, Second Military Medical University, Xiangyin Road No. 800, Yangpu District, Shanghai 200433, China. (CH) Tel: +86 2181870970 8002; Fax: +86 216533 4333; E-mail: huangcaiguo@ @otmail.com; (BJ) Tel: +86 2181870970 8001;Fax: +86 216533 4333; E-mail: jiaobh@live.cn

or B Wang, Key Laboratory of Experimental Marine Biology, Institute of Oceanology, Chinese Academy of Sciences, Qingdao, China.Tel: +8653282898553 ; Fax: +86 532 82898612; E-mail: wangbingui@gmail.com

${ }^{3}$ These authors contributed equally to this work.

Keywords: Wentilactone B; SMMC-7721 cells; cell cycle arrest; apoptosis; MAPK pathway

Abbreviations: DCFH/DA, 2',7'-dichlorofluorescin diacetate; DMSO, dimethyl sulfoxide; ERK, extracellular signal-regulated kinase; $\mathrm{H}_{2} \mathrm{O}_{2}$, hydrogen peroxide; HCC, Hepatocellular carcinoma; INVDOCK, ligand-protein inverse docking program; JNK, c-Jun $\mathrm{NH}_{2}$-terminal kinase; MAPK, mitogen-activated protein kinase; NAC, $\mathrm{N}$-acetylcysteine; $\mathrm{O}_{2}^{-\bullet}$, superoxide radical; $\mathrm{OH}^{-}$, hydroxylradical; ROS, reactive oxygen species; SPR, surface plasmon resonance; z-VAD-fmk, Caspase inhibitor $\mathrm{N}$-benzyloxycarbonyl-Val-Ala-Asp-fluoromethylketone

Received 08.2.13; revised 28.4.13; accepted 30.4.13; Edited by A Stephanou
} 
The small G-protein Ras, or its downstream effector Raf, could link receptor and non-receptor tyrosine kinases to downstream serine/threonine kinases. ${ }^{17}$ The mitogenactivated protein kinases (MAPK) whose activities are regulated by Ras/Raf expression are mainly composed of three members: extracellular signal-regulated kinases (ERKs), c-Jun N-terminal kinases (JNKs) and p38 MAPKs. In general, the ERK signaling is typically associated with cell survival, proliferation and differentiation activated by mitogenic stimuli, ${ }^{18,19}$ whereas the JNK and p38 cascades are activated by chemicals and environmental stress and are usually involved in cell growth and apoptosis. ${ }^{20}$

It is well known that marine natural products have a vital role in cancer chemotherapy. Wentilactone B (WB) (EN-48-57), a tetranorlabdane diterpenoid extracted from the marine algaederived endophytic fungus Aspergillus wentii EN-48, displayed potent cytotoxic activity. ${ }^{21}$ Recently, the antitumor activity of WB has attracted our attention. It has been previously demonstrated that WB could suppress the growth of various tumor cell lines, especially human hepatoma SMMC-7721 cells, by triggering apoptosis and inhibiting metastasis. ${ }^{22}$ However, the underlying mechanisms of its anticancer properties are poorly understood.

In the present study, WB was found to induce G2 phase arrest and apoptosis in SMMC-7721 cells. WB treatment significantly suppressed tumor growth in vivo. Furthermore, it was demonstrated that WB could bind to Ras and induce G2 phase arrest via the ERK/MAPK signaling. In parallel, through the JNK/MAPK cascade, it induced apoptosis. Consequently, WB may be a potential compound for the development of anticancer agents for HCC.

\section{Results}

WB triggers cell cycle arrest at G2 phase and regulates the expression of cell cycle-regulating proteins. Our recent studies demonstrated that WB exerted a potent cytotoxic activity and had a significantly inhibitory effect on several tumor cells. ${ }^{22}$ Compared with the other hepatoma cell lines (HepG2, Huh7 and Hep3B), a marked antiproliferative activity was observed in SMMC-7721 cells with $\mathrm{IC}_{50}$ value of $18.96 \mu \mathrm{m}$ after treatment of WB for $48 \mathrm{~h}$ (Supplementary Figure S1).

To explore the mechanisms leading to the loss of SMMC7721 cells proliferation by WB, the effects of WB treatment on cell cycle arrest were first examined. SMMC-7721 cells were incubated with various concentrations of WB and $5-\mathrm{FU}$ for different time periods. A time-dependent and dose-dependent G2/M phase arrest was observed (Figure 1a and Supplementary Figure S2). While the well known cytotoxic-anti-cancer-agent 5 -FU resulted in a progressive increase in the population of cells in G0/G1 phase, which is consistent with the previous studies. ${ }^{23,24}$ Furthermore, western blot analysis showed that WB treatment caused a marked time-dependent increase in the phosphorylation status of p53, cdc2 and cdc25C, and in the level of p21, whereas the total level of cdc2, cdc25C and cyclin B1 were decreased (Figure 1b). These results suggest that inhibition of proliferation of SMMC-7721 cells by WB may involve G2/M phase arrest, possibly through alterations of p53, p21 and G2/M phase cell cycle-related protein expression.
WB induces mitochondrial-related apoptosis. Next, the SMMC-7721 cells were treated with 5-FU and various concentrations of WB for the indicated time periods, and the apoptotic cells were detected. As observed in Figure 2a and Supplementary Figure S3, WB treatment resulted in a marked time-dependent and dose-dependent increase in apoptosis. Moreover, the WB $(18.96 \mu \mathrm{m})$ showed a similar effect with 5 -FU $(20 \mu \mathrm{m})$ at $48 \mathrm{~h}$, and a better effect than $5-\mathrm{FU}$ at $72 \mathrm{~h}$. Additionally, treatment with WB activated caspase-9, -7 and PARP, but not caspase-8. Significant proteolytic cleavage of caspase-9, -7, -3 and PARP was detected, but not of caspase-8 (Figure 2b). Consistently, it was shown that cytochrome $c$ (Cyt $c$ ) was released from the mitochondria to the cytosol (Figure 2c), indicating the activation of the intrinsic apoptosis pathway. Meanwhile, decreased levels of antiapoptotic Bcl-xl, -2 and phospho-Bad, and increased expression of Bad and phospho-Bcl-2 were observed (Figure 2d and Supplementary Figure S4).

To further assess the effects of WB on the mitochondrial apoptotic pathway, the mitochondrial membrane potential $\left(\Delta \psi_{\mathrm{m}}\right)$ was measured using fluorochrome dye JC-1. As shown in Figures $2 \mathrm{e}$ and $\mathrm{f}$, WB treatment resulted in a time-dependent significant decrease in the ratio of the green fluorescence (FITC) to red fluorescence (PE). Furthermore, the caspase inhibitor $\mathrm{N}$-benzyloxycarbonyl-Val-Ala-Asp-fluoromethylketone (z-VADfmk) significantly, but not entirely, prevented an increase in the proportion of apoptotic cells (Figure 2g). It restored the expression of $\mathrm{Bcl}-\mathrm{xl}$ and PARP. Otherwise, the inhibitor blocked the cleavages of caspase- 3 and PARP, and it decreased the expression of Bad (Figure $2 \mathrm{~h}$ ). These results reveal that WBinduced apoptosis was partially mediated by the mitochondrial pathway and caspase activation, accompanying Cyt $c$ release from the mitochondria into the cytosol.

The accumulation of ROS induced by WB participates in the apoptosis of SMMC-7721 cells. ROS, generally considered as a mediator of caspase-independent cell death, also has an important role in the effects of various anticancer agents on cell cycle transitions. ${ }^{15,25}$ Thus, the intracellular ROS level was measured using the fluorescent probe $2^{\prime}, 7^{\prime}$-dichlorofluorescin diacetate (DCFH/DA). Figures 3a and $b$ show that WB increased the mean DCF fluorescence markedly, indicating that WB could potentiate the elevation of intracellular ROS. Next, to determine whether increased production of ROS may have a role in WB-induced apoptosis or cell cycle arrest, we treated the cells with the antioxidant $\mathrm{N}$-acetylcysteine (NAC) $1 \mathrm{~h}$ before adding WB for a further 48-h treatment. The results showed that pretreatment with NAC caused a significant inhibition of the WB-induced increase of cell apoptosis (Figures $3 c$ and $d$ ). However, the same treatment did not prevent the WB-induced increase in the G2/M population (Figures $3 e$ and $\mathrm{f}$ ).

Additionally, pivotal proteins associated with apoptosis and the $\mathrm{G} 2 / \mathrm{M}$ transition were investigated to interpret the role of ROS in WB's antineoplastic effects. Western blot analysis revealed that NAC blocked the cleavage of caspase-3 and PARP, and it decreased the expression of Bad, although the expression of $\mathrm{Bcl}-\mathrm{xl}$, caspase-3 and PARP were increased significantly (Figure $3 g$ ). In contrast, NAC did not restore the expression of the G2/M transition-related proteins (Figure $3 \mathrm{~h}$ ). 
a

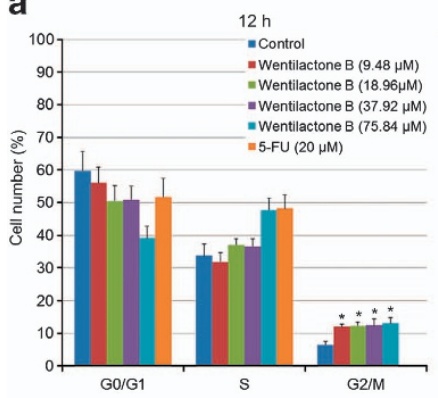

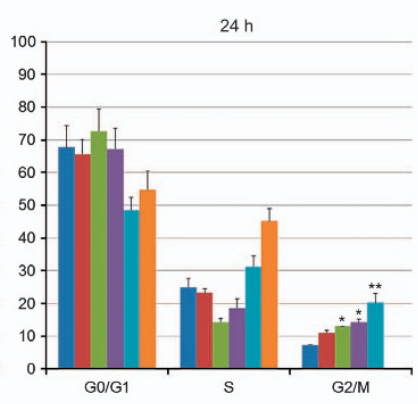
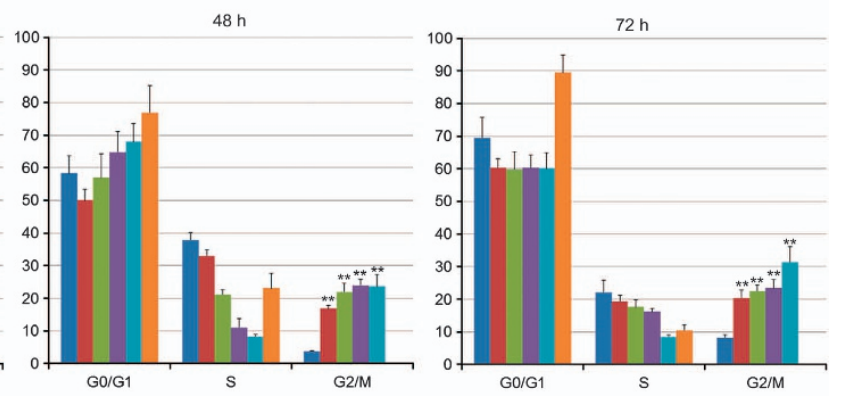

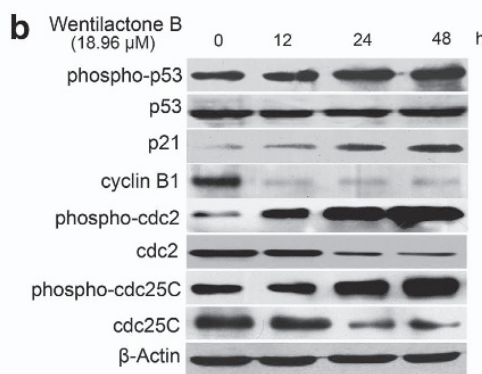

Figure 1 Cell cycle analysis of WB-treated cells. (a) SMMC-7721 cells were treated with 5 -FU $(20 \mu \mathrm{m})$ and WB $(9.48,18.96,37.92$ and $75.84 \mu \mathrm{m})$ for four different time points. Then, the cell cycle distribution was measured using flow cytometry. The percentage of cells in each population was shown as the mean \pm S.D. from three independent experiments. ${ }^{*} P<0.05$, ${ }^{\star *} P<0.01$. (b) Western blot analysis of $\mathrm{p} 53, \mathrm{p} 21$ and $\mathrm{G} 2 / \mathrm{M}$ transition-related proteins after WB treatment. Similar experiments were repeated at least twice with similar results

Similarly, NAC failed to influence the altered expression of JNK, ERK, p53 and p21 (Figure 3i). Taken together, these findings indicate that WB-induced apoptosis was at least partially mediated by an ROS-dependent apoptosis pathway, and the induction of the G2 phase arrest did not involve ROS.

ERK and JNK regulate WB-induced G2 phase arrest and apoptosis, respectively. Considerable evidence indicates that MAPK signaling cascades regulate not only cell growth, development and differentiation, but also apoptosis and cell growth arrest. ${ }^{26,27}$ To understand the mechanism by which WB affects MAP kinase activation, the role of WB in the activation of ERK, JNK and p38 MAP kinase was determined. Both western blot and ELISA showed that the phosphorylation of ERK and JNK was gradually, and significantly, increased after WB treatment, but the phosphorylation of p38 was hardly affected (Figures $4 a$ and b). Interestingly, from Figures $4 \mathrm{c}$ and $\mathrm{d}$, it can be seen that only the JNK inhibitor SP600125 significantly restored cell apoptosis in response to WB, and only the ERK inhibitor U0126 had a hard reversible effect on the G2 phase cell cycle arrest induced by WB. At the protein level, the results were consistent with the results of flow cytometry and revealed that the U0126 had an apparently opposite effect on the WB-induced G2/M transition-related proteins, but it did not significantly affect the apoptosis-related proteins. On the contrary, the SP600125 exerted apparently opposite effects on the WB-induced apoptosis proteins, but it did not affect the G2/M transition-related proteins (Figures $4 \mathrm{e}$ and f). From the results obtained so far, it could be concluded that the cell apoptosis and G2 phase arrest of SMMC-7721 cells induced by WB were mediated by activation of the JNK/MAPK signaling and the ERK/MAPK signaling, respectively.
WB activates MAPK through a Ras-dependent pathway. It has been demonstrated that Ras, a GTP-binding protein, is a common upstream activator of the Raf/MEK pathway. ${ }^{28,29}$ Thus, the results achieved above led us to consider whether Ras is involved in WB-induced apoptosis and cell cycle arrest. The specific antibodies for Ras-GTP and phospho-c-Raf were proportional to the amount of the active form of Ras. ${ }^{30}$ Firstly, the activation of Ras induced by WB in SMMC-7721, HepG2 and Huh7 cells were analyzed by western blot. As shown in Figure 5a, WB induced the activation of Ras in all the three cells, whereas SMMC-7721 cells exerted a remarkable activation of Ras. Additionally, WB could result in the activation of Ras and the phosphorylation of c-Raf in SMMC-7721 cells in a time-dependent manner (Figure 5b). Therefore, the activation of Ras might involve in the phosphorylation of MAPK induced by WB. To address the question, the cells were transfected with a dominant-negative Ras (RasN17) and then treated with WB for $48 \mathrm{~h}$. The induction of apoptosis and cell cycle distribution of cells subjected to those treatments were determined. As shown in Figures $5 \mathrm{c}$ and $\mathrm{d}$, and Supplementary Figure S5, RasN17 significantly suppressed both cell apoptosis and G2 phase arrest induced by WB. Similarly, western blot analysis revealed that the abnormal expressions of cell apoptosisrelated and G2/M transition-related proteins were restored to normal as a result of RasN17 expression. Moreover, RasN17 suppressed the activation of ERK and JNK (Figure 5e).

To further investigate the possible targets of WB, an inverse docking (INVDOCK) analysis was applied to identify proteins that WB can directly bind to. Using the INVDOCK program,69 cancer-related proteins were extracted from the Protein Data Bank. Of these, five proteins were closely related to MAPKs (Table 1). As Ras-GTP, an activated 
4

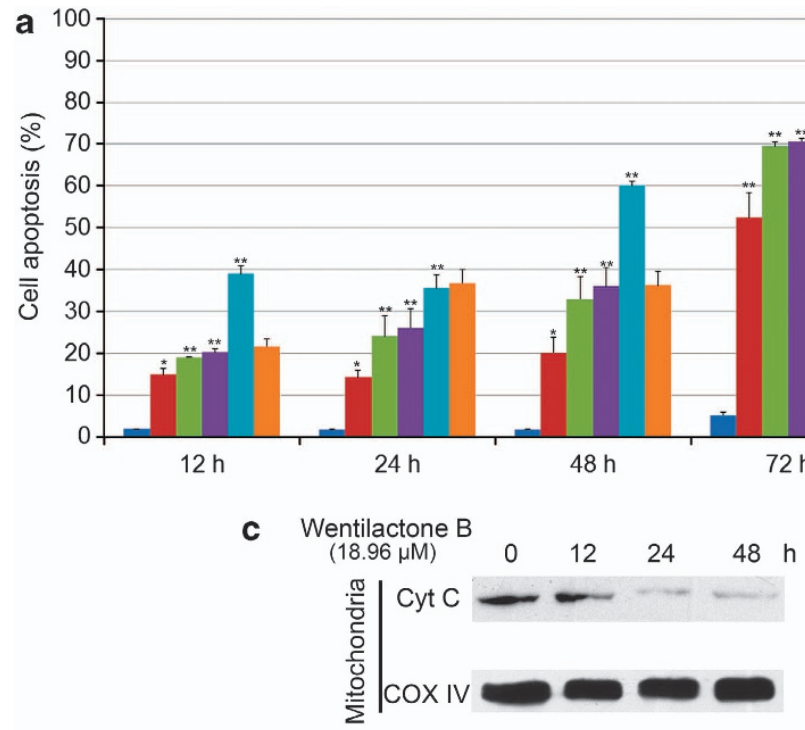

- Wentilactone B (9.48 $\mu \mathrm{M})$

- Wentilactone B (18.96 $\mu \mathrm{M})$

- Wentilactone B $(37.92 \mu \mathrm{M})$ - Wentilactone B (75.84 $\mu \mathrm{M})$

b
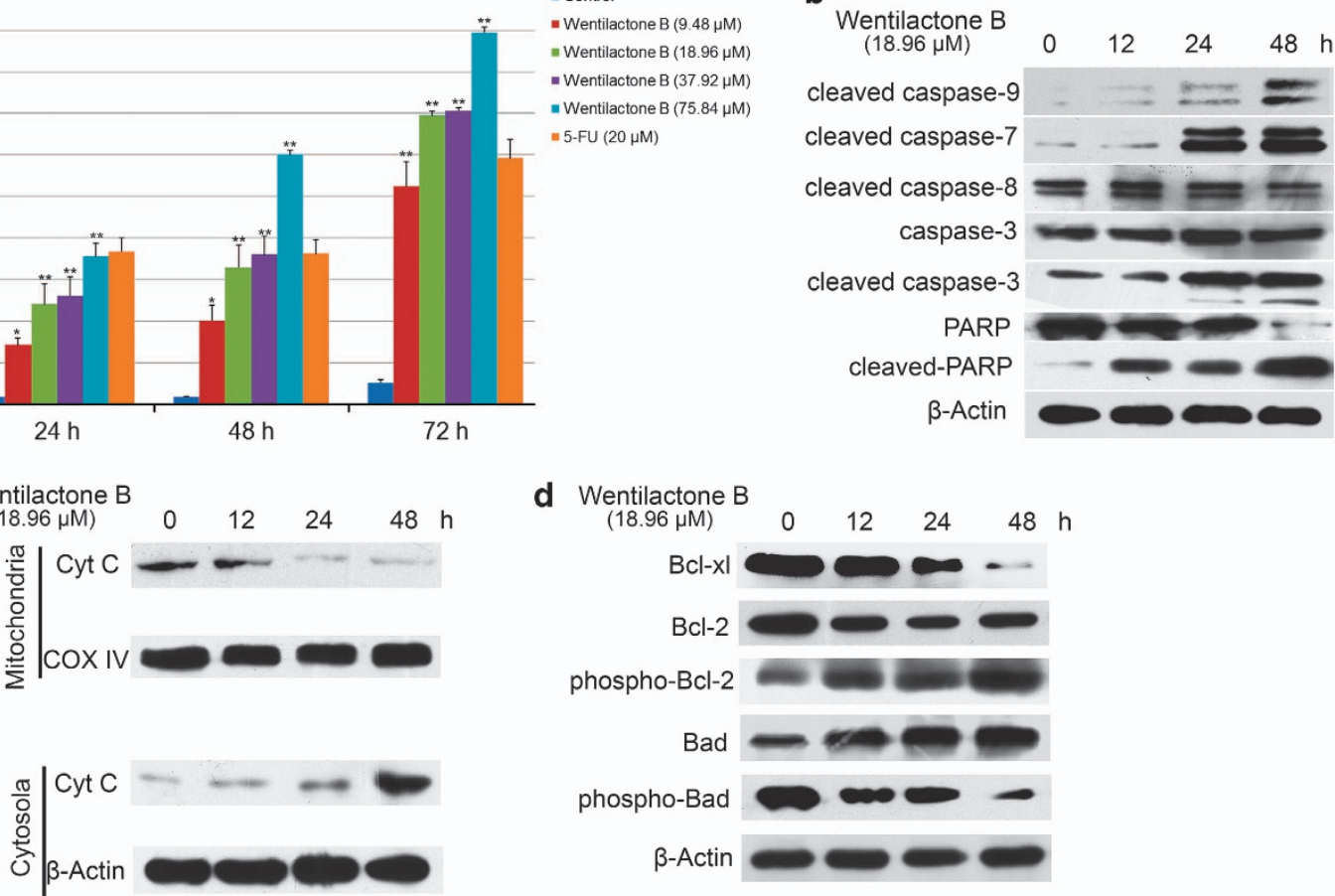

d Wentilactone $B$ $(18.96 \mu \mathrm{M})$

0

$12 \quad 24$

$48 \mathrm{~h}$

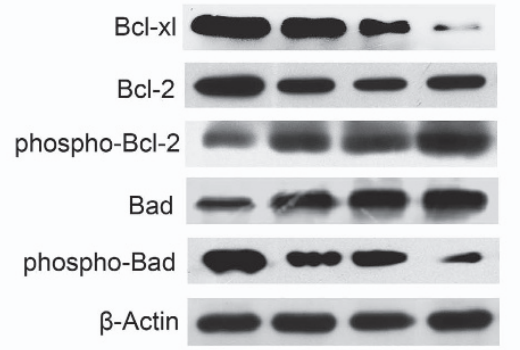

e

Wentilactone B

$(18.96 \mu \mathrm{M})$
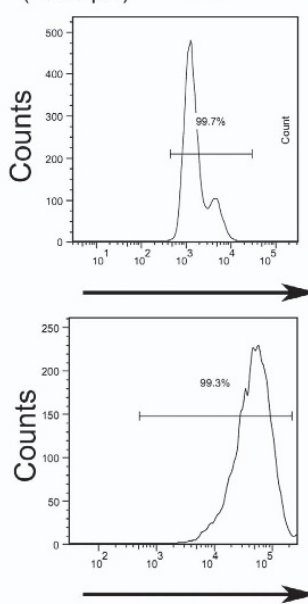

- FITC

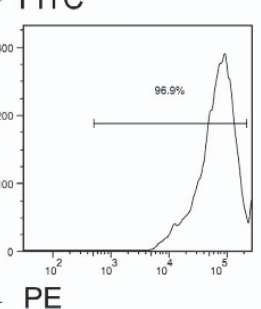

g

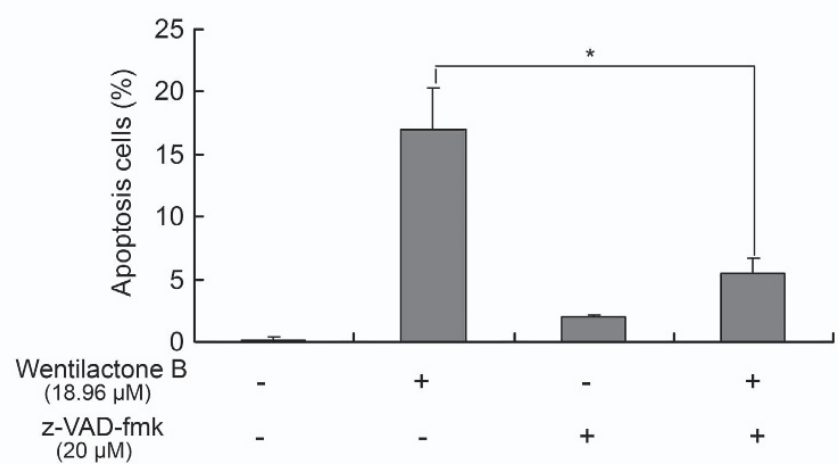

$12 \mathrm{~h}$
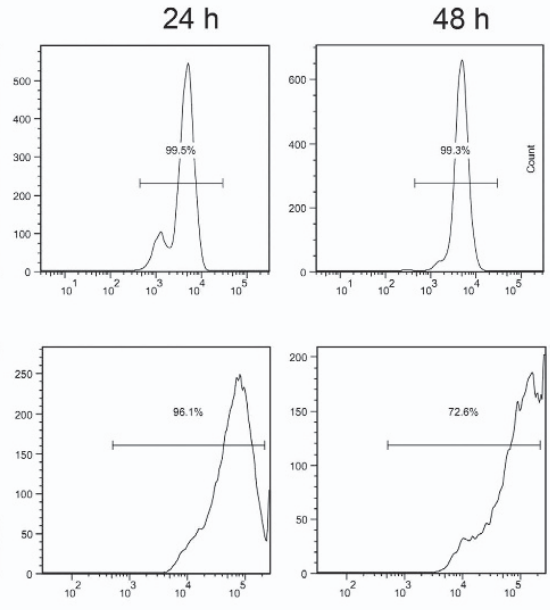

h

Wentilactone B (18.96 $\mu \mathrm{M})$

(20 $\mu \mathrm{M})$
-VAD-fm

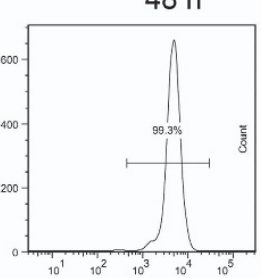

Bad

$\mathrm{Bcl}-\mathrm{xl}$

cleaved caspase-3

caspase-3

cleaved-PARP

PARP $=-$

B-Actin 20 
form of Ras, has a high affinity for numerous downstream effectors, ${ }^{31,32}$ its three-dimensional (3-D) structure was chosen to explore its binding interaction with WB. The illustration of WB docked to Ras-GTP using the INVDOCK program is shown in Figure 5f. Furthermore, the binding ability of WB to the Ras-GTP and RasN17 mutant protein was determined by surface plasmon resonance (SPR). Moreover, the binding affinity of WB to the proteins was reflected by response unit $(R U)$ values. The $R U$ increased apparently following the WB concentrations increasing, with the equalitism dissolution $K_{\mathrm{D}}=47 \mu \mathrm{M}$ in the plot of WB to Ras-GTP (Figure $5 \mathrm{~g}$ ). While the binding between WB and RasN17 mutant protein showed a significantly lower $R U$ value, with $K_{\mathrm{D}}=527 \mu \mathrm{m}$ (Figure 5h), indicating that WB may have a specific binding affinity toward Ras-GTP. Together, these results suggest that WB may activate MAPK via a Rasdependent pathway.

WB suppressed the tumor growth in mouse xenograft models. To further evaluate whether WB inhibits tumor growth in vivo, $2 \times 10^{6}$ SMMC-7721 cells were subcutaneously inoculated into nude mice. WB treatment was begun on the first day, and it was administered at 5, 10 and $20 \mathrm{mg} /$ $\mathrm{kg}$ intraperitoneally for 21 days, with dimethyl sulfoxide (DMSO) as the negative control and 5-FU as the positive control. The data showed that the tumor growth inhibition was gradually evident following the dose increase, where $\sim 86.4 \%$ inhibition of tumor growth was observed at a dose of $20 \mathrm{mg} / \mathrm{kg} /$ day (Figure 6a). The tumor mass of WB (10 and $20 \mathrm{mg} / \mathrm{kg}$ )-treated mice was significantly less than that of the control group (Figure 6b). Compared with the control, WB (10 and $20 \mathrm{mg} / \mathrm{kg}$ ) treatment suppressed the tumor growth on days 16 and 20 (Figure $6 \mathrm{c}$ ). Although 5-FU inhibited the tumor growth and size significantly, the body weight of 5-FUtreated mice decreased strongly during the course of treatment. By contrast, an increase in body mass was observed in the WB-treated groups (Figure 6d). Moreover, the activation of Ras inWB-treated xenograft tissues was analyzed. WB treatment apparently resulted in the upregulation of Ras-GTP, but not of the total Ras (Figure 6e). To further substantiate the activation of MAPK pathway that WB induced in vivo, the activation of ERK, JNK and p38 in xenograft tissues was revealed by immunohistochemistry. The results showed that both ERK and JNK were activated in WB-treated xenograft tissues, whereas p38 remained unchanged (Figure 6f). These results suggest that WB was an effective agent that could inhibit the growth of transplanted HCC tumors in vivo.

\section{Discussion}

In the present study, we demonstrated that WB significantly suppressed tumor growth in vivo and in vitro. Moreover, the compound triggered cell cycle arrest at G2 phase and induced cell apoptosis via a different MAPK signaling pathway.

Treatment with WB in SMMC-7721 cells resulted in G2 phase arrest in a time- and dose-dependent manner, and reduced the levels of phospho-p53, p21 and G2/M transitionrelated proteins. The reduced activity of cdc25C and a subsequent increase in cdc2 phosphorylation is the hallmark of cell cycle arrest at the G2/M phase. ${ }^{33}$ It is suggested that cdc25C regulates entry into mitosis by regulating the activation of cdc2/cyclin B1. Although cdc25C only has low activity in its unphosphorylated form, following hyperphosphorylation, it will efficiently catalyze the activation of cdc2/ cyclin B1. ${ }^{34}$ On the other hand, the complex of cdc2/cyclin B1 could phosphorylate cdc25C. ${ }^{35,36}$ Indeed, cell cycle analysis revealed a prominent $\mathrm{G} 2$ phase arrest in WB-treated cells, and phospho-p53, -cdc2, -cdc25C and p21 were upregulated. To the contrary, cyclin B1, cdc2 and cdc25C were downregulated. It is plausible that alterations in cell cycleassociated proteins may lead to the arrest of G2 phase in WB-treated cells.

Apoptosis, a fundamental process essential for development and maintenance of tissue homeostasis, is a major mechanism to eliminate cancer cells. ${ }^{37}$ Thus, an effective strategy for cancer prevention and treatment seems to target signaling intermediates in the apoptosis-inducing pathways. ${ }^{38}$ Here, we showed that following WB treatment, a time- and dose-dependent apoptosis was observed. As an important signal for apoptotic cell death in mammalian cells, mitochondrial apoptosis is thought to be the principal target of the survival signaling system. ${ }^{39}$ Mitochondria commit to apoptosis via increased permeability of the outer mitochondrial membrane, decreased $\Delta \Psi_{\mathrm{m}}$, release of Cyt $c$ and production of ROS. ${ }^{40}$ Following the treatment of SMMC-7721 cells with WB, we observed that WB treatment induced a significant increase of proteolytic cleavage of caspase-9, -7, -3 and PARP, but not of caspase-8. The caspase inhibitor z-VAD-fmk almost halted the compound-induced apoptosis, suggesting that WB-induced apoptosis was mainly mitochondria-dependent. Meanwhile, a time-dependent increase in cytosolic Cyt $c$ as a result of release from mitochondria was observed in WB-treated cells, indicating activation of the intrinsic mitochondria apoptosis pathway. Furthermore, considerable evidence indicates that both proapoptotic and antiapoptotic Bcl-2 family proteins were implicated in apoptosis induced by an antitumor

Figure 2 WB induces apoptosis in SMMC-7721 cells through mitochondrial disruption. (a) Following treatment of SMMC-7721 cells with 5-FU (20 $\mu \mathrm{M})$ and various concentrations of WB for the indicated time points, apoptotic cells were detected by Annexin $\mathrm{V}$ and propidium iodide double staining. Statistical analysis of the percentages of the apoptotic cells. The data shown are representatives of three experiments. ${ }^{*} P<0.05,{ }^{* \star} P<0.01$. (b) SMMC-7721 cells were treated with or without $18.96 \mu \mathrm{m}$ WB for the indicated time, and then the cells were harvested and lysed. Caspase- $3,-7,-8,-9$ and PARP were measured by western blot. (c) After treatment, the cells were harvested and separated into cytosolic and mitochondrial fractions. The expressions of Cyt $c$ in the cytosol and mitochondria were analyzed by western blot. (d) Western blots of whole-cell extracts of SMMC-7721 cells were analyzed for Bcl-xl, Bcl-2, phospho-Bcl-2, Bad and phospho-Bad after treatment with $18.96 \mu \mathrm{m}$ WB for the indicated time. (e) The disruption of mitochondrial transmembrane potential of SMMC-7721 cells that were treated or not with $18.96 \mu \mathrm{m}$ WB was measured by flow cytometry using the fluorochrome dye JC-1. (f) The ratio of PE/FITC indicates the depolarized mitochondrial membrane. Each value is the mean \pm S.D. of three determinations. ${ }^{\star} P<0.05$, ${ }^{\star \star} P<0.01$. (g) Broad-spectrum caspase inhibitor z-VAD-fmk partially inhibited WB-induced apoptosis. The SMMC-7721 cells were treated with z-VAD-fmk for $1 \mathrm{~h}$ before adding WB for another $48 \mathrm{~h}$. Apoptosis was measured by flow cytometry as described above. " $P<0.05$. (h) SMMC-7721 cells were treated with $20 \mu \mathrm{m} z$-VAD-fmk for $1 \mathrm{~h}$ before treatment with $18.96 \mu \mathrm{M}$ WB for $48 \mathrm{~h}$. The whole-cell extracts were assessed by western blot 
a Wentilactone B
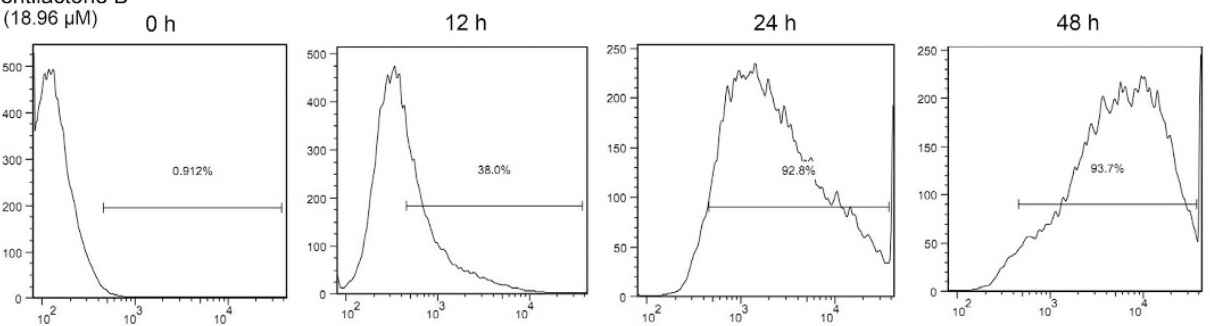

C
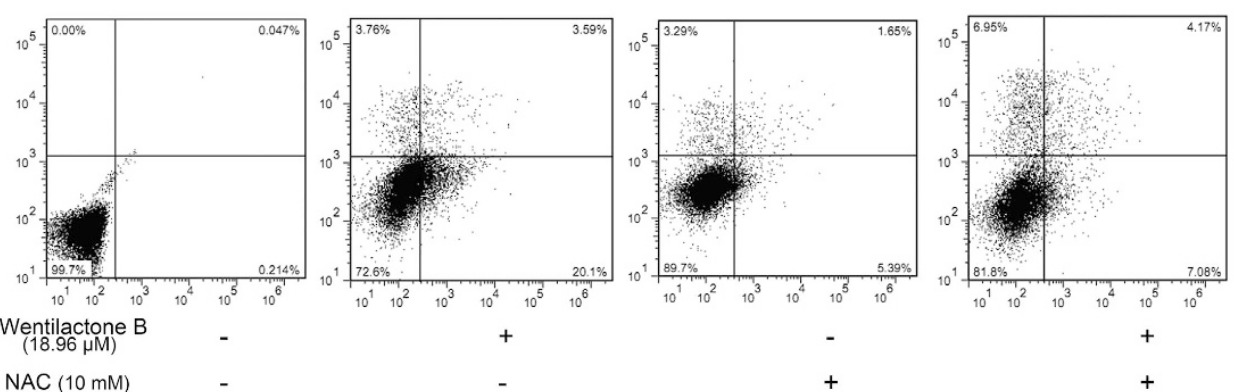

b

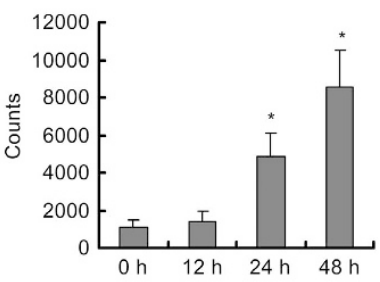

d

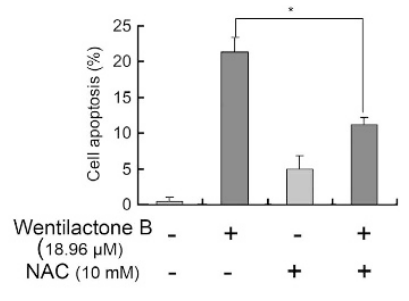

e

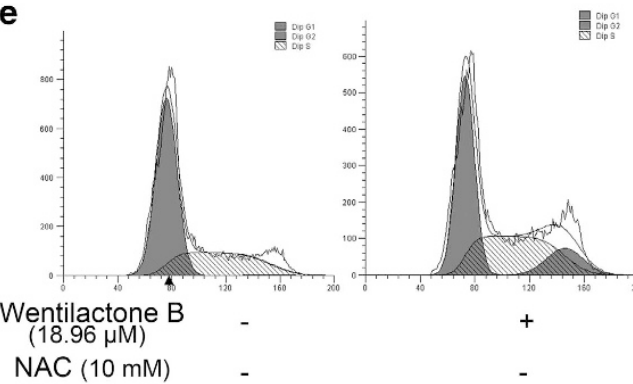

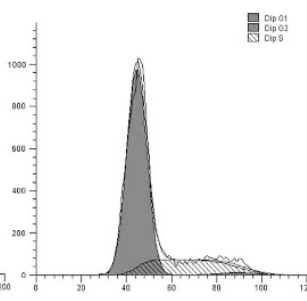

$-$
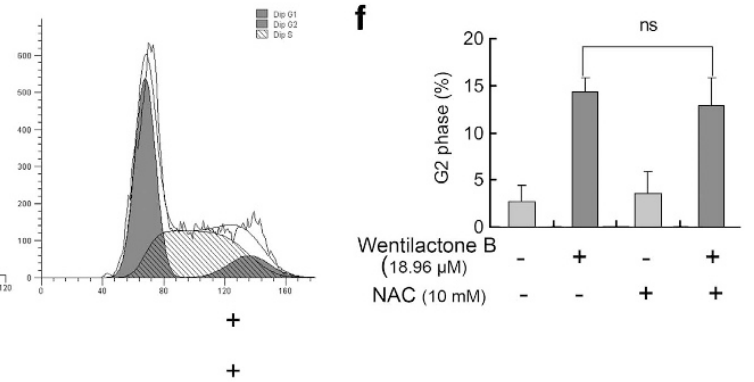

g

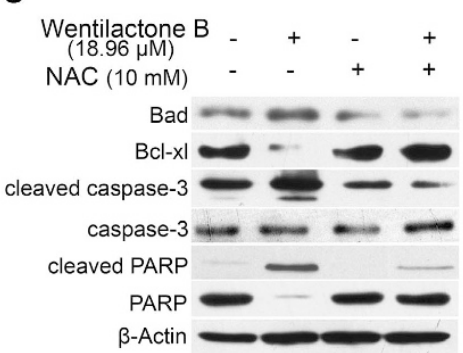

h

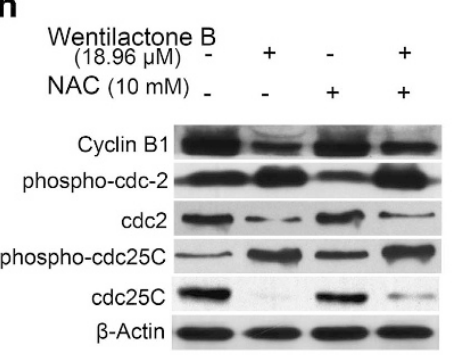

i

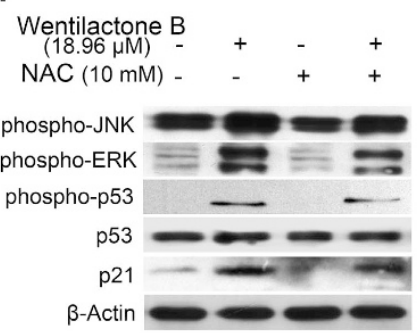

Figure 3 WB potentiates the elevation of ROS, which contributes to SMMC-7721 cells' apoptosis, but not the G2 phase arrest. (a) SMMC-7721 cells were treated with WB $(18.96 \mu \mathrm{m})$ for the indicated time points and then loaded with DCFH/DA. The mean DCF fluorescence was measured by flow cytometry. (b) Histograms are representative of the percentage of DCF fluorescence of three independent experiments. ${ }^{*} P<0.05$. (c) The cells were preincubated for $1 \mathrm{~h}$ in the presence or absence of NAC (10 mM), and then $18.96 \mu \mathrm{m}$ WB was added and incubated for $48 \mathrm{~h}$. The induction of apoptosis was determined by flow cytometry. (d) Statistical analysis of the percentages of the apoptotic cells. Data shown are from representative experiments repeated three times with similar results. ${ }^{*} P<0.05$. (e) The cells were incubated for $1 \mathrm{~h}$ in the presence or absence of NAC $(10 \mathrm{~mm})$, and then $18.96 \mu \mathrm{m}$ WB was added and incubated for $48 \mathrm{~h}$. Then, the cell cycle distribution was analyzed using flow cytometry. (f) The percentage of cells in each population is shown as the mean \pm S.D. from three independent experiments. ns, not significant. (g-i) Cells were treated with $10 \mathrm{~mm}$ NAC for $1 \mathrm{~h}$ before treatment with $18.96 \mu \mathrm{m}$ WB for $48 \mathrm{~h}$. The whole-cell extracts were assessed by western blot

compound. ${ }^{41}$ Consistently, the downregulation of $\mathrm{Bcl}-\mathrm{xl}$ and $\mathrm{Bcl}-2$, and upregulated proapoptotic Bad were detected in the WB-treated cells, which is consistent with apoptosis induction.

A number of studies have proven that excess ROS production and/or antioxidant depletion are associated with the apoptotic response induced by several anticancer agents, such as isoobtusilactone $\mathrm{A}$ and tamoxifen. ${ }^{42,43}$ Evidence also suggests that ROS participated in the diallyl tri-sulfide- induced G2/M phase cell cycle arrest in human prostate cancer cells. ${ }^{44}$ Our results showed that WB-induced apoptosis was accompanied by the accumulation of ROS, and pretreatment with the inhibitor NAC partially prevented WB-induced increase of apoptosis, although it almost did not repair WB-induced G2 phase arrest, indicating that ROS-dependent apoptotic pathways and ROS-independent G2/M phase arrest were involved in WB-mediated cell death. 
a
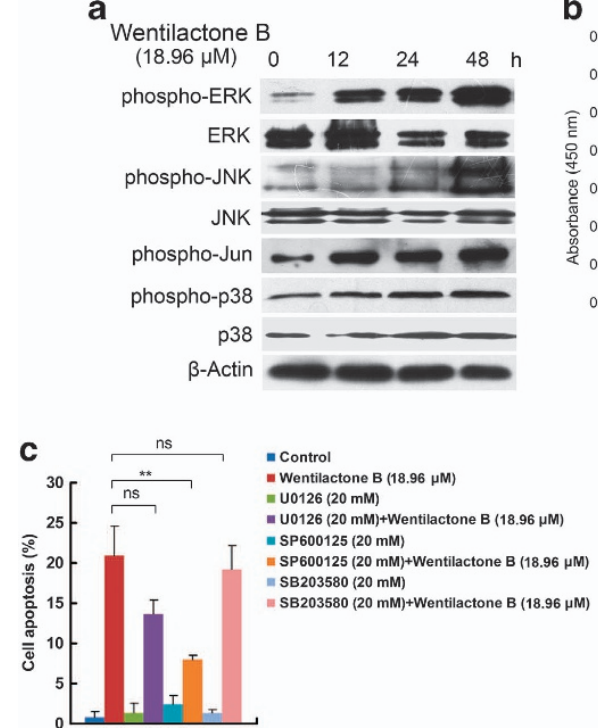

e

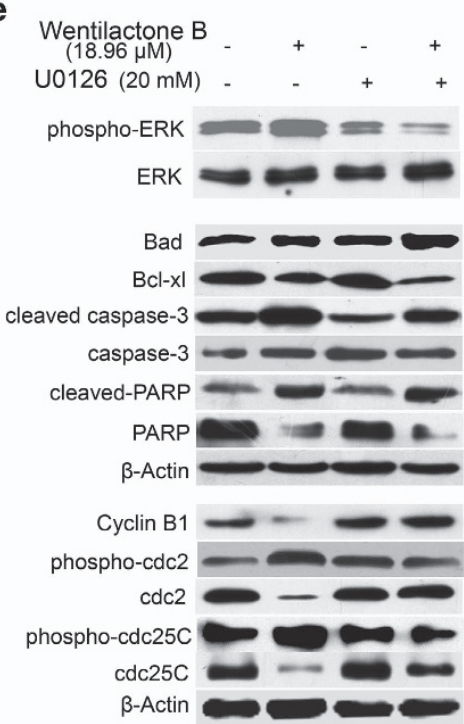

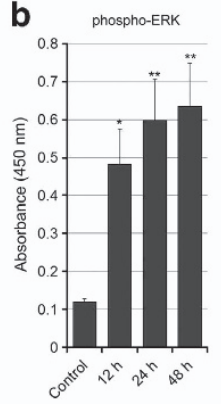
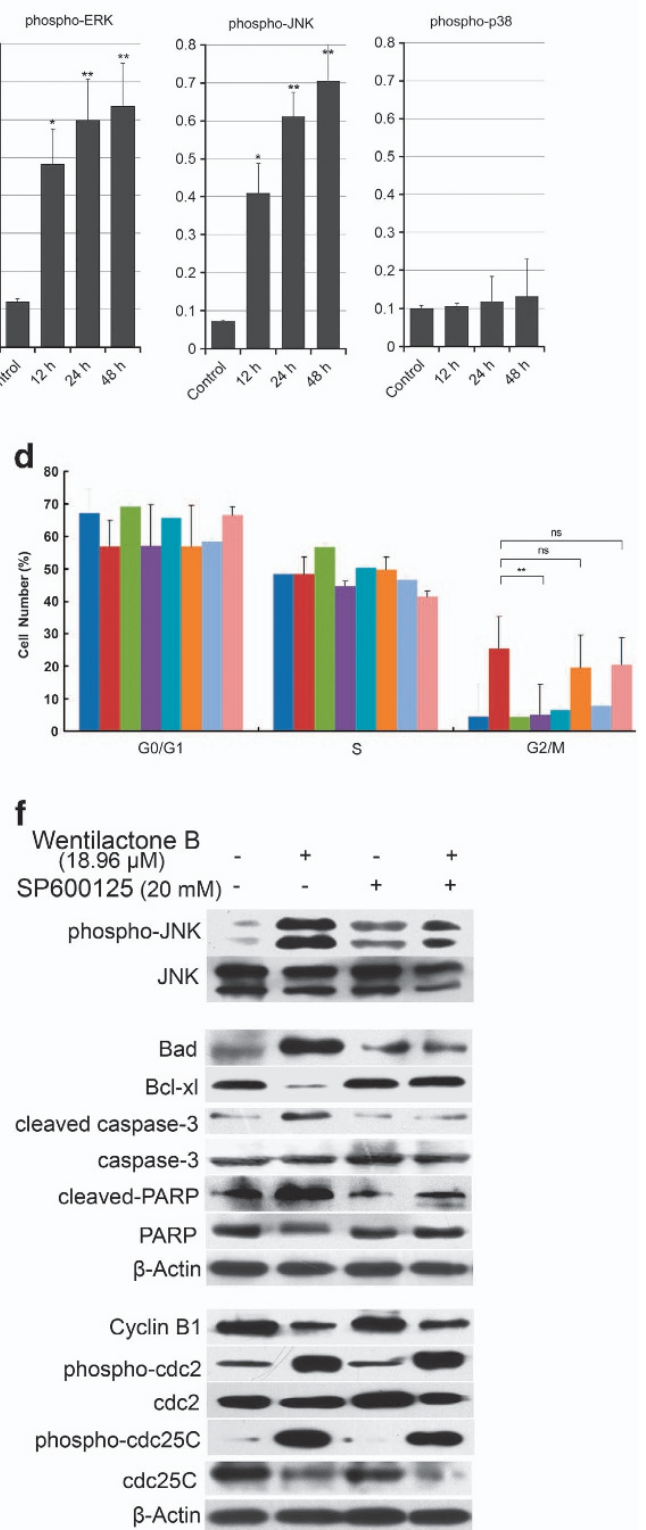

Figure 4 ERK regulates WB-induced G2 phase arrest, and JNK participates in WB-induced apoptosis in SMMC-7721 cells. (a) Effects of WB on ERK, JNK, and p38 MAP kinase activation in SMMC-7721 cells. SMMC-7721 cells were treated with or without $18.96 \mu \mathrm{M}$ WB for the indicated time, and then the cells were harvested and lysed. The phosphorylation levels of ERK, JNK and p38 MAP kinase were analyzed by western blot. (b) SMMC-7721 cells were pretreated with $18.96 \mu \mathrm{m}$ WB for the indicated time points. Cells were analyzed for phosphorylated ERK, JNK and p38 by InstantOne ELISA. ${ }^{*} P<0.05,{ }^{* \star} P<0.01$. (c, d) The cells were incubated for $1 \mathrm{~h}$ in the presence or absence of U0126 (20 mM), SP600125 (20 mM) and SB203580 (20 mM), and then $18.96 \mu \mathrm{m} \mathrm{WB}$ was added followed by incubation for an additional $48 \mathrm{~h}$. The induction of apoptosis and cell cycle distribution were determined by flow cytometry. The percentage of cell apoptosis and cell cycle distribution were shown as the mean \pm S.D. from three independent experiments. ${ }^{*} P<0.01$; ns, not significant. (e, f) Cells were preincubated for $1 \mathrm{~h}$ in the presence or absence of U0126 (20 mM) and SP600125 (20 mM), and then treated with $18.96 \mu \mathrm{M}$ WB, followed by western blot analysis of various apoptosis and cell cycle-related proteins

Significant attention has been focused on the important role of the MAPK pathway, and several key signaling components and phosphorylation events that have a role in regulating the cell cycle, apoptosis and even tumorigenesis. ${ }^{27,45}$ Among the MAPK subfamilies, p38 has been shown to be essential for sustained G2/M arrest and apoptosis induced by various anticancer agents. ${ }^{46}$ However, our data excluded the possibility that p38 is involved in apoptosis and G2/M phase arrest induced by WB. Treatment with WB did not lead to a significant change in the phosphorylation status of p38 and the total level expression of it; second, with or without the inhibitor SB230580, apoptosis and the cell cycle of the cells treated with WB did not exert a significant change. Among the other MAPK subfamilies, activation of the ERK pathway has long been associated with proliferation and growth, and the apoptotic signaling pathways in some cases. The JNK pathway is generally responsible for the apoptotic response induced by several DNA-damaging agents. ${ }^{47}$ Based on our results, compared to phospho-p38, the levels of phospho-ERK and -JNK increased in a time-dependent 


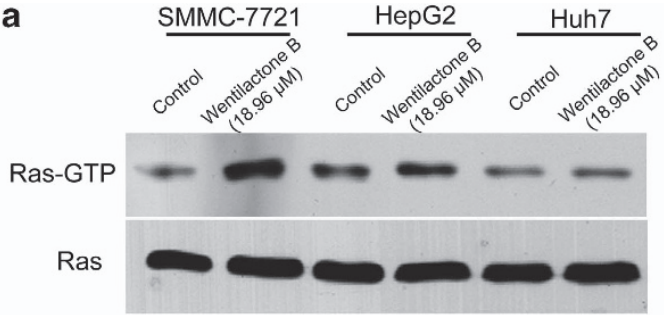

b

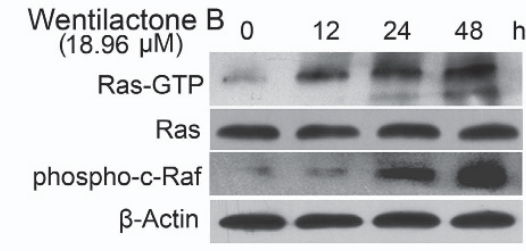

e
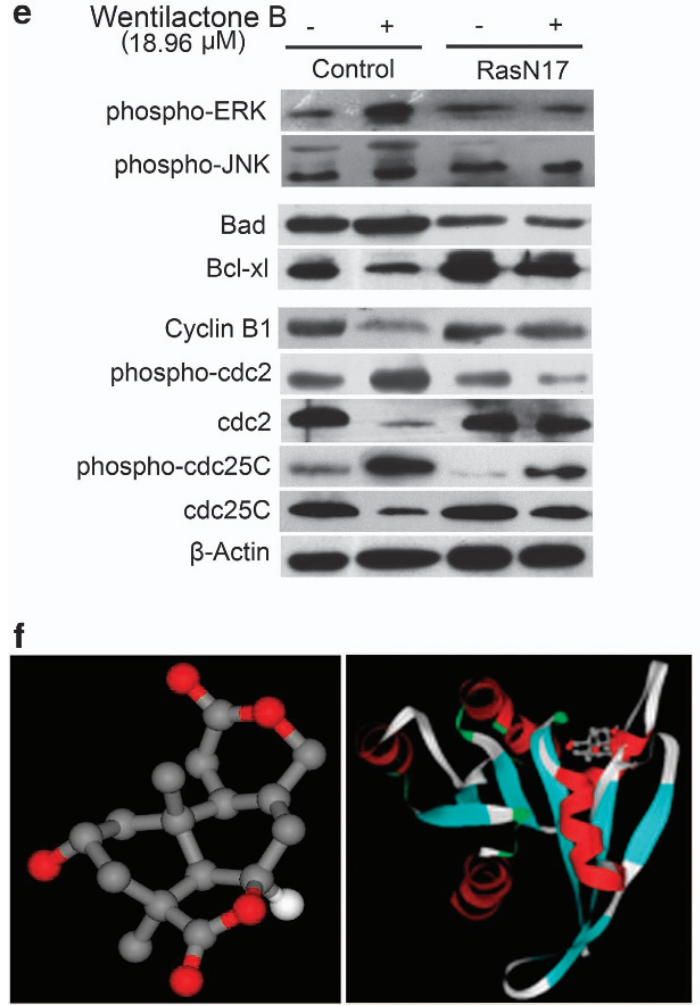

C
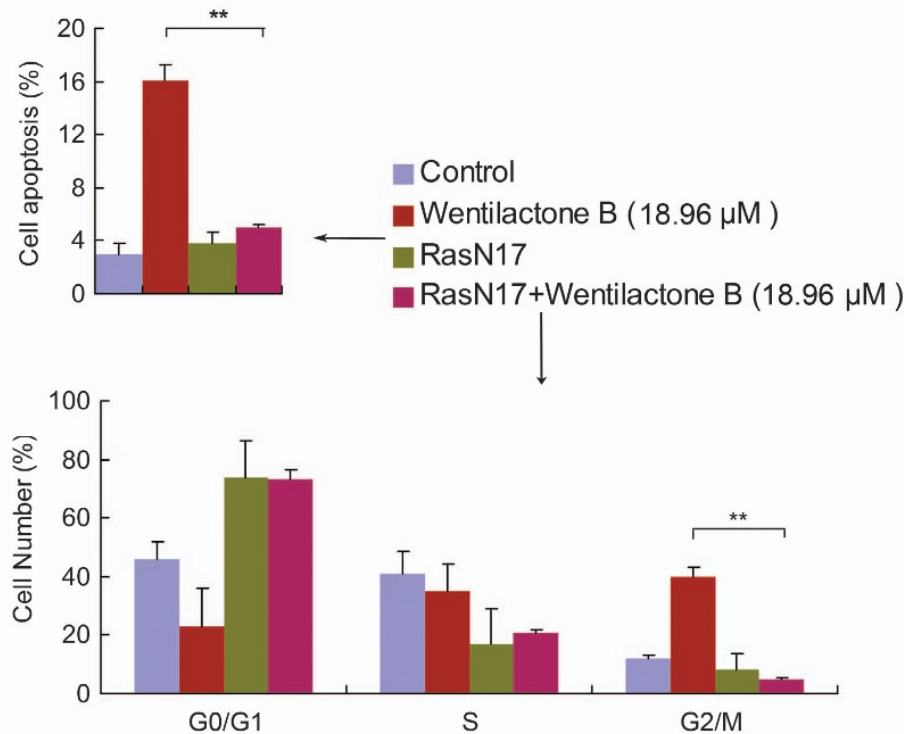

g

Wentilactone B to Ras-GTP
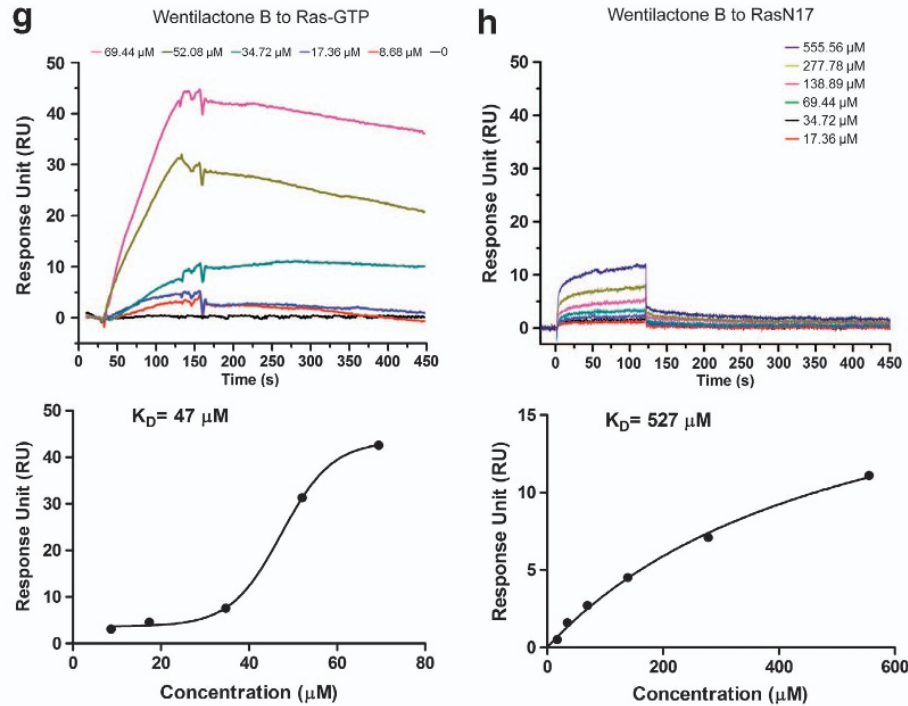

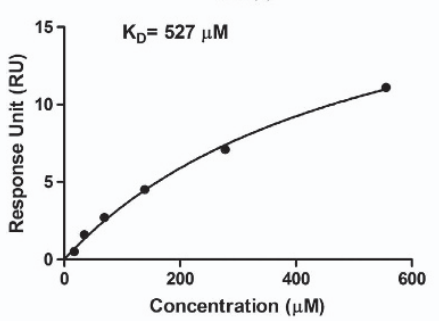

Figure 5 WB binds to Ras to exert its effects. (a) Three hepatoma cell lines (SMMC-7721, HepG2 and Huh7) were treated with WB (18.96 $\mu \mathrm{M})$ for $48 \mathrm{~h}$, then the RAS activity was analyzed by western blot. (b) Time course for WB-induced Ras activation. SMMC-7721 cells were stimulated by WB for the indicated time and lysed. The cellular content of the active forms of Ras (Ras-GTP and phospho-c-Raf) was analyzed. (c, d) The SMMC-7721 cells that were transfected with RasN17, or empty vector were incubated with $18.96 \mu \mathrm{m} \mathrm{WB}$ for $48 \mathrm{~h}$. The induction of apoptosis and cell cycle distribution were determined by flow cytometry. The percentage of cell apoptosis and cell cycle distribution are shown as the mean \pm S.D. from three independent experiments. ${ }^{* *} P<0.01$ compared with no WB treatment in RasN17-transfected SMMC-7721 cells. (e) The cells that were transfected with RasN17 or empty vector were incubated with $18.96 \mu \mathrm{m}$ WB for $24 \mathrm{~h}$, and then the cellular contents of the phosphorylation levels of ERK and JNK, apoptosis and cell cycle-related proteins were analyzed by western blot. (f) The verification of WB binds to Ras-GTP. Left: the three-dimensional structure of WB; right: illustration of the WB molecule docked into the Ras-GTP protein, modeled using the INVDOCK program. $(\mathbf{g}, \mathbf{h})$ The binding affinity of WB for the Ras-GTP protein and the RasN17 protein determined by SPR

manner after WB treatment. More interestingly, the flow cytometry analyses revealed that only JNK inhibitor markedly inhibited WB-induced apoptosis, and only ERK inhibitor significantly abolished WB-induced G2 phase arrest, suggesting that ERK may mainly operate in G2/M phase arrest, and JNK predominantly controls WB-induced apoptosis. Additionally, our results showed that the activation of ERK was involved in the accumulation of phospho-cdc2, which might be due to the decrease of cdc25C activation by phosphorylation, resulting in subsequent G2 arrest, and JNK activation is involved in the events of WB-mediated apoptosis, which is predominantly inhibited by the JNK inhibitor SP600125. Undoubtedly, these results show that the ERK signaling mediate $\mathrm{G} 2 / \mathrm{M}$ phase arrest, as 
well as the JNK cascades have a role in WB-induced apoptosis (Figure 7).

Several chemotherapeutic agents are reported to exert their effects by inducing the Ras/Raf/MAPK pathway. ${ }^{48}$ Ras is a common upstream activator of the Raf/MAPK pathway. ${ }^{28,29}$

Table 1 The proteins predicted by INVDOCK to bind to Wentilactone B (WB)

\begin{tabular}{lcccc} 
Compound Protein & $\begin{array}{c}\text { Protein data } \\
\text { bank identifica- } \\
\text { tion number }\end{array}$ & Species & $\begin{array}{c}\text { Ligand-protein } \\
\text { interaction } \\
\text { energy value }\end{array}$ \\
\hline WB & HRas & P01112 & Human & -45.9 \\
& BRaf1 & P15056 & Human & -52.5 \\
& PAK4 & O96013 & Human & -43.6 \\
& P53 & P04637 & Human & -40.3 \\
& CDK2 & P24941 & Human & -44.4 \\
\hline
\end{tabular}

Abbreviation: INVDOCK, inverse docking program.
A recent study showed that the phosphorylation of the Ras/ MAPK signaling was profoundly associated with liver carcinogenesis, and acyclic retinoid, which inhibited Ras/MAPK activation, successfully prevented HCC recurrence. ${ }^{49}$ Our data, however, showed that the level of Ras and the phosphorylation of c-Raf were increased after WB treatment, suggesting that the Ras signaling is activated by WB. To further understand the mechanisms of how Ras/Raf activate the MAPK pathway that is induced by WB, SMMC7721 cells were transfected with RasN17. WB-induced apoptosis and G2 phase arrest were both abolished by the dominant-negative mutants of RasN17. Thus, the Ras/Raf signaling may have a key role in WB-induced activation of the ERK and JNK cascades (Figure 7).

It is well accepted that small-molecule drugs generally exert their therapeutic functions by binding to the cavities of proteins to influence their biological activities. ${ }^{50}$ To confirm the results
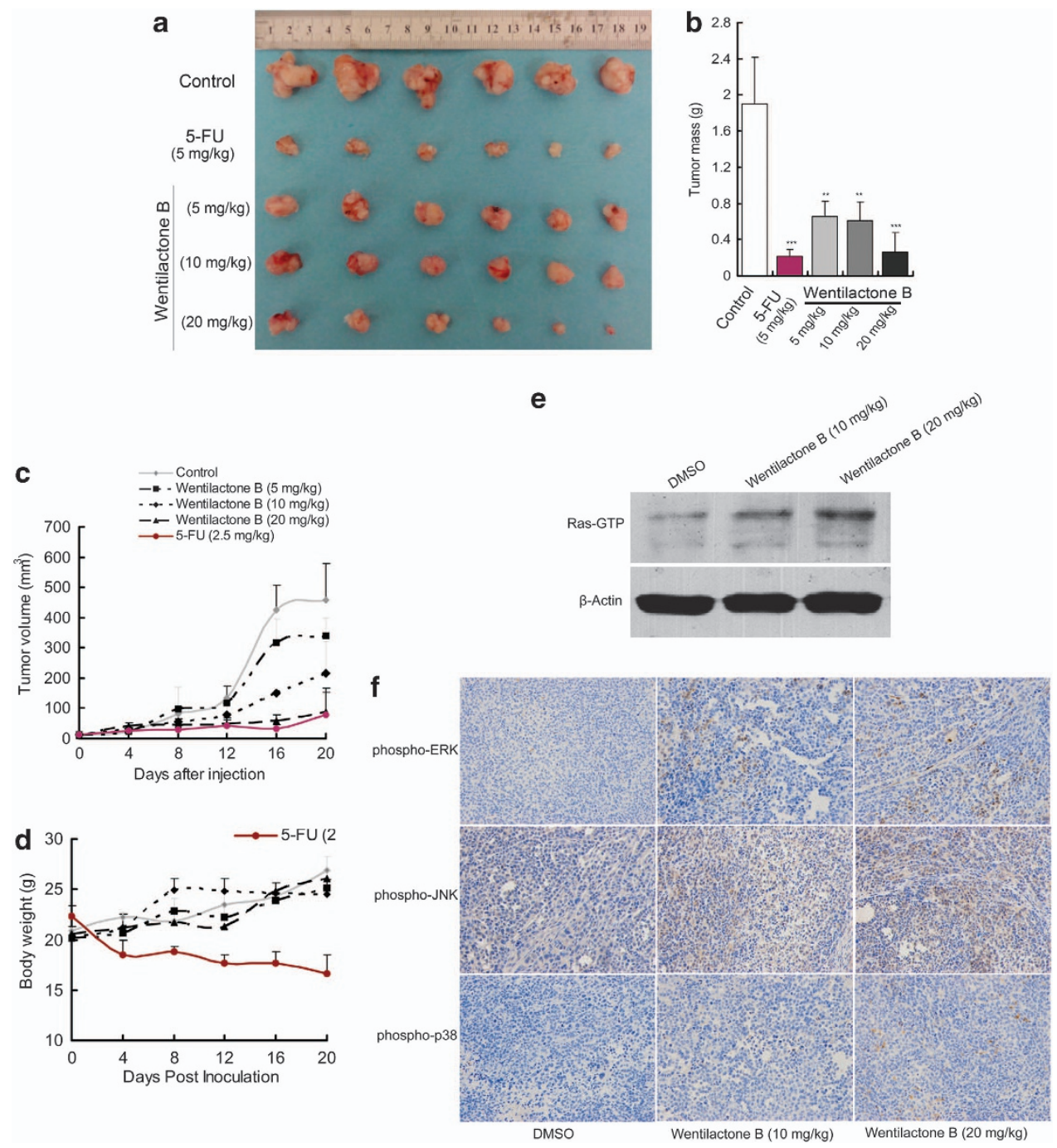

Figure 6 The effects of WB treatment on the tumorigenicity of SMMC-7721 cells in vivo. (a) In total, $2 \times 10^{6}$ SMMC-7721 cells/mouse were subcutaneously inoculated into nude mice. The 50 mice were randomised into five groups and treated with WB, 5-Fu and DMSO, as described in the Methods once every 2 days for 20 days. The resulting tumors were excised from the animals after treatment. (b) The tumor masses for five groups of animals were compared, and each histogram represented the mean \pm S.D. of 10 mice. ${ }^{* *} P<0.01 ;{ }^{* * *} P<0.001$. (c) The tumor volumes of the nude mice inoculated with SMMC-7721 cells were measured and calculated once every 2 days. (d) The nude mouse body weight was measured every 4 days. (e) The expression of Ras and Ras-GTP in tumor xenograft tissues was analyzed by western blot. (f) The phosphorylation of ERK, JNK and p38 in tumor xenograft tissues was revealed by immunohistochemistry 


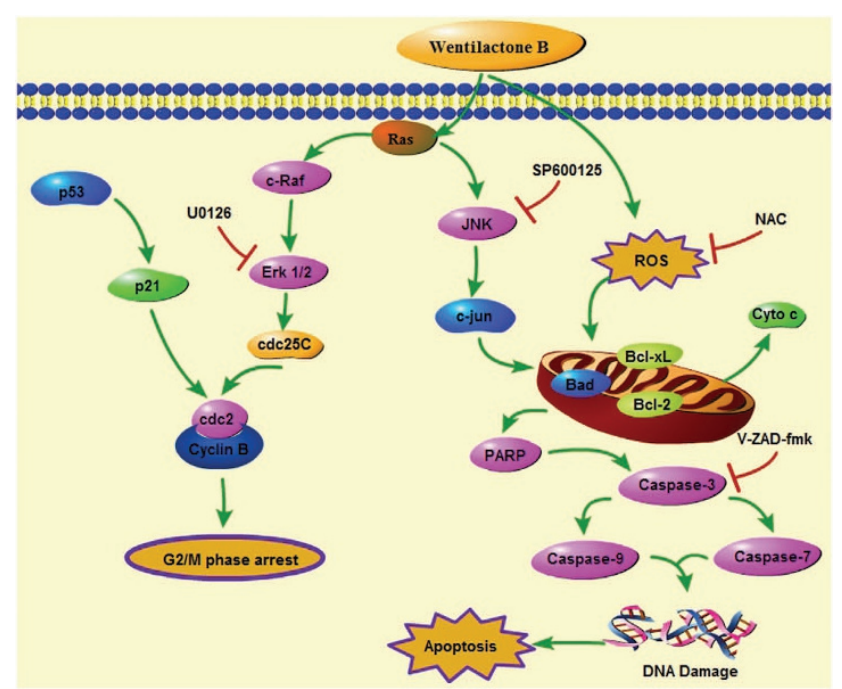

Figure 7 Overview of the pathways for WB-induced apoptosis and cell cycle arrest in SMMC-7721 cells

obtained from the experiments and to further investigate the possible targets of WB, an INVDOCK analysis was applied to identify proteins that WB may directly bind to. From our results, 69 cancer-related proteins whose expressions were significantly changed following WB treatment were identified. Of these, p53 and the protein kinase superfamily members HRas, BRaf, PAK4 and CDK2 are all closely related to MAPKs. Among the five proteins, HRas and BRaf are the upstream molecular components of the MAPK pathway. ${ }^{31,32}$ It has been suggested that alterations of the Ras/Raf/MAPK pathway may be involved in human cancer due to irregular activation of receptor tyrosine kinases or gain-of-function mutations mainly in the RAS or RAF genes. ${ }^{45}$ Additionally, Ras-GTP has a high affinity for numerous downstream effectors. $^{32}$ Thus, the 3-D structure of Ras-GTP was selected to predict the WB-binding ability through the INVDOCK analysis. The INVDOCK was designed to confirm the proteintial targets related with WB-induced antineoplastic effect, and the results note that WB could directly bind to Ras-GTP. In addition, the binding affinity of WB toward Ras-GTP was confirmed using SPR biosensor analysis, suggesting that Ras-GTP might bind directly to WB to activate the downstream pathway.

In conclusion, the present study describes the general molecular mechanisms of the antitumor effects of WB in human hepatoma SMMC-7721 cells. WB could significantly induce cell cycle arrest at G2 phase and mitochondrial-related apoptosis. Moreover, the compound arrests the cell cycle at the G2/M phase through the Ras/Raf/ERK signaling, and induces apoptosis via the Ras/Raf/JNK signaling. We also show that WB binds to Ras/Raf to activate the downstream MAPK pathway to exert its effects. In addition, both in vitro and in vivo, WB could significantly inhibit HCC growth. Thus, WB, as a potential agent, holds good promise as a new, effective strategy for treating HCC.

\section{Materials and Methods}

Chemicals and reagents. WB, which was isolated from the marine algaederived endophytic fungus Aspergillus wentii EN-48 by the Institute of Oceanology of the Chinese Academy of Sciences, was dissolved at a concentration of $1 \mathrm{mg} / \mathrm{ml}$ in $100 \%$ DMSO as a stock solution, and stored at $-20{ }^{\circ} \mathrm{C}$. It was diluted with cell culture media before use. ${ }^{21}$ The final DMSO concentration did not exceed $0.1 \%$ throughout the study.

Dulbecco's modified Eagle's medium (DMEM), fetal bovine serum (FBS), trypsinEDTA, penicillin and streptomycin were purchased from Biowest (Maine et Loire, France); DMSO was obtained from Amresco (Solon, OH, USA). DCFH/DA, the BCA protein assay kit, the JC-1 (the probe $5,5^{\prime}, 6,6^{\prime}$-tetrachloro-1, $1^{\prime}, 3,3^{\prime}$-tetraethylbenzimidazolcarbocyanine iodide) detection kit, the Annexin V-FITC apoptosis detection kit, the cell cycle detection kit, NAC, the Caspase inhibitor z-VAD-fmk, the JNK inhibitor (SP600125), the p38 inhibitor (SB230580) and the ERK1/2 inhibitor (U0126) were all purchased from Beyotime (Jiangsu, China). All antibodies used in this study were purchased from Cell Signaling Technologies Inc. (Beverly, MA, USA). The chemoluminescence reagent was obtained from Millipore (Billerica, MA, USA). The pCMV vector encoding dominant-negative Ras (RasN17) and the control vector were purchased from Clontech (Takara Biomedical Technology Co., Ltd., Beijing, China). The RasN17 mutant protein was expressed and purified on the base of the vector (RasN17), and some validation was shown in Supplementary Figure S6. Human recombinant protein Ras-GTP (purify $\geq 90 \%$ ) was purchased from Abcam (Hong Kong, China). All other chemicals were of analytical grade.

Cell line and cell culture. The human hepatoma cell lines SMMC-7721, HepG2, Huh7 and Hep3B were obtained from the Cell Bank of Type Culture Collection Chinese Academy of Sciences (Shanghai, China) and cultured in DMEM. The cell cultures were supplemented with 10\% FBS and 1\% penicillin/ streptomycin in a humidified $5 \% \mathrm{CO}_{2}$ incubator at $37^{\circ} \mathrm{C}$.

Cell proliferation assay. The cells were treated with various concentrations of WB or 5-FU for 24,48 and $72 \mathrm{~h}$, respectively. The cell growth was determined by Cell counting kit-8 assay (Dojindo, Kumamoto, Japan) according to the manufacturer's protocol. Experiments were performed in triplicate.

Detection of the cell cycle stage. To determine the cell cycle distribution, $1 \times 10^{6}$ cells were collected after drug treatment and fixed in $70 \%$ ethanol at $4{ }^{\circ} \mathrm{C}$ overnight. Then, the cells were labeled with PI $(1 \mathrm{mg} / \mathrm{ml})$ in the presence of $1 \%$ RNase A for $30 \mathrm{~min}$. The fractions of the cells in G0/G1, S and G2/M phase were analyzed by flow cytometry at an excitation wavelength of $488 \mathrm{~nm}$, and an emission wavelength of $630 \mathrm{~nm}$.

Detection of apoptotic cells. The percentage of apoptotic cells was measured using an Annexin V-FITC apoptosis detection kit, according to the manufacturer's protocol. The cells $\left(5 \times 10^{5}\right)$ were cultured in six-well plates and were grown to $70 \%$ confluence. After treatment for different durations, the cells were harvested and washed twice with PBS, and then resuspended in $200 \mu \mathrm{l}$ binding buffer containing $2.5 \mu \mathrm{l}$ Annexin V-FITC. After incubation away from light for $10-15 \mathrm{~min}$ at room temperature, the cells were centrifuged and resuspended again in $300 \mu \mathrm{l}$ binding buffer containing $5 \mu \mathrm{l}$ of PI. The stained cells were then analyzed using a flow cytometer.

Measurement of mitochondrial transmembrane potential. The fluorescent lipophilic cationic probe JC-1 detection kit was used to detect the change of mitochondrial transmembrane potential by flow cytometry. The treated cells were harvested and washed with PBS. Then, samples containing $10^{6} \mathrm{cells} / \mathrm{ml}$ were stained with prepared JC-1 solution containing $5 \mu \mathrm{lJC}-1(200 \times), 800 \mu \mathrm{l}$ water and $200 \mu \mathrm{l} \mathrm{JC}-1(5 \times)$ binding buffer for $30 \mathrm{~min}$ at $37^{\circ} \mathrm{C}$. The cells were washed and resuspended in $500 \mu \mathrm{l}$ PBS, and the fluorescence was monitored at excitation/emission wavelengths of $490 / 540 \mathrm{~nm}$ (red) and 540/590 nm (green). Changes in the ratio between the red and green fluorescence were used as an indicator of changes in the mitochondrial membrane potential. The data analysis was performed with Cell Quest software (Becton Dickinson, Singapore, Singapore) by measuring both the green and red JC-1 fluorescence.

Measurement of ROS generation. Intracellular ROS production was detected using the peroxide-sensitive fluorescent probe DCFH-DA, as previously described. ${ }^{51}$ In brief, the cells were incubated in the absence or presence of treatment for the indicated time. Then, the cells were harvested and suspended in $1 \mathrm{~mm}$ of DCFH-DA at $37^{\circ} \mathrm{C}$ for $30 \mathrm{~min}$. After treatment with DCFH-DA, the cells were washed twice with PBS and resuspended in PBS for detection of ROS accumulation using the FACS Calibur flow cytometry system at a wavelength pair of $488 / 538 \mathrm{~nm}$. 
ELISA assay. The activation of ERK, JNK and p38 MAKP in cell lysates, which were treated with WB for different time points were measured using a human InstantOne ELISA kit (eBioscience, San Diego, CA, USA), following to the manufacturer's protocol and instructions. Optical density was read using the InstantOne assay plate-96-well at $450 \mathrm{~nm}$. The amounts of phosphorylated ERK, JNK and P38 MAPK were calculated according to the manufacturer's protocol. All tests were performed in triplicate.

Western blot analysis. After the cells were seeded into six-well plates and treated with WB for the indicated time, cell lysates were prepared. The protein concentration was quantified using a BCA protein assay kit (Beyotime). Equal amounts of protein were separated using SDS-PAGE and transferred to nitrocellulose membranes, followed by incubation with the appropriate primary and secondary antibodies. The immunocomplexes were visualized using a horseradish peroxidase-conjugated antibody, followed by a chemoluminescence reagent (Millipore) and detected on photographic film.

Transfection procedure. The cells were transfected with dominantnegative Ras (RasN17) and a control vector using Lipofectamine 2000, according to the manufacturer's instructions. Positive selection was performed after incubating the cells in fresh medium for $48 \mathrm{~h}$. G418-resistant colonies at a concentration of $0.7 \mathrm{mg} / \mathrm{ml}$ were selected, and transfected clones were used for further studies after 2 weeks of selection.

In vivo tumor xenograft study. A total of $2 \times 10^{6}$ SMMC-7721 cells/ mouse were subcutaneously inoculated into the right flank of nude mice. One week later, 50 mice were randomised into five groups and treated with WB $(5,10$ and $20 \mathrm{mg} / \mathrm{kg}), 5-\mathrm{Fu}(5 \mathrm{mg} / \mathrm{kg}$, positive control) and DMSO (20 mg/kg, dissolved in sodium chloride, negative control) once every 2 days for 21 days. The tumor volumes and mouse body size were measured once every 4 days. On day 20, the mice were killed and the tumor tissues were weighed. The following formula was used for tumor volume measurement: tumor volume $=L \times W^{2} / 2$, where $L$ is the length and $W$ is the width. The Ethical Committee of the Second Military Medicine University approved the current study.

Immunohistochemistry. The tumor xenograft tissue blocks were cut into $4-\mu \mathrm{m}$ sections and fixed with formalin, embedded with paraffin. Samples were first incubated with primary antibodies against phospho-ERK, -JNK and -p38, and then incubated with a biotinylated secondary antibody using the ChemMate EnVision Kit (K5001, DAKO, Hamburg, Germany). All stained sections were examined under a light microscope at a magnification of $\times 200$. For the histological analysis, the sections were stained with $\mathrm{H} \& \mathrm{E}$, according to the manufacturer's instructions.

Statistical analysis. The data are expressed as the mean \pm S.D. Significant differences between the two groups were determined by Student's t-test, and $P<0.05$ was considered to be statistically significant.

Prediction of possible targets for WB. To predict the possible protein targets for WB, ligand-protein INVDOCK program was applied to identify protein cavities that WB can directly bind to. As Ras-GTP is a common upstream activator of MAPK, its 3-D structure was used to verify the targeting of WB.

SPR biosensor analysis. SPR biosensor analysis was used to verify the binding of WB to Ras-GTP protein and RasN17 protein, which were analyzed by the Center for Bio-information Technology, Chinese Academy of Sciences Shanghai, China, using an SPR-based Biacore T100 instrument (GE Healthcare, Pittsburgh, PA, USA), as described previously. ${ }^{52}$ In brief, the proteins were immobilized on a CM5 sensor chip in $7000 \mathrm{RU}$ according to the standard primary amine-coupling procedures. WB was diluted to different concentrations with a constant DMSO concentration of $0.5 \%$ in running buffer, and it was then injected into the channels for protein binding at a flow rate of $10 \mu \mathrm{l} / \mathrm{min}$, followed by washing with the running buffer. The $K_{\mathrm{D}}=K_{\mathrm{off}} / K_{\mathrm{on}}$ (where, $K_{\mathrm{D}}=$ equilibrium dissociation constant, $K_{\text {on }}=$ association rate constant and $K_{\text {off }}=$ dissociation rate constant) were determined by analysis of the sensorgram curves obtained at different concentrations of WB by use of BIA evaluation v4.1 (Biacore).

\section{Conflict of Interest}

The authors declare no conflict of interest.
Acknowledgements. This research project was supported by the National Basic Research Program of China (973 Program) (2010CB833800), by the National Ocean 863 Project of the Ministry of Science and Technology of China (2011AA09070110) and by the Natural Science Foundation of China (31270403).

1. Siegel R, Ward E, Brawley O, Jemal A. Cancer statistics, 2011: the impact of eliminating socioeconomic and racial disparities on premature cancer deaths. CA Cancer J Clin 2011; 61: 212-236.

2. Yang JD, Roberts LR. Hepatocellular carcinoma: A global view. Nat Rev Gastroenterol Hepatol 2010; 7: 448-458.

3. Carr BI. Hepatocellular carcinoma: current management and future trends. Gastroenterology 2004; 127: S218-S224.

4. Tang TC, Man S, Lee CR, Xu P, Kerbel RS. Impact of metronomic UFT/cyclophosphamide chemotherapy and antiangiogenic drug assessed in a new preclinical model of locally advanced orthotopic hepatocellular carcinoma. Neoplasia 2010; 12: 264-274.

5. Gamet-Payrastre L, Li P, Lumeau S, Cassar G, Dupont MA, Chevolleau S et al. Sulforaphane, a naturally occurring isothiocyanate, induces cell cycle arrest and apoptosis in HT29 human colon cancer cells. Cancer Res 2000; 60: 1426-1433.

6. Huang WW, Ko SW, Tsai HY, Chung JG, Chiang JH, Chen KT et al. Cantharidin induces G2/M phase arrest and apoptosis in human colorectal cancer colo 205 cells through inhibition of CDK1 activity and caspase-dependent signaling pathways. Int J Oncol 2011; 38: 1067-1073.

7. Dorée $\mathrm{M}$, Galas $\mathrm{S}$. The cyclin-dependent protein kinases and the control of cell division. FASEB J 1994; 8: 1114-1121.

8. Parker LL, Piwnica-Worms H. Inactivation of the p34cdc2-cyclin B complex by the human WEE1 tyrosine kinase. Science 1992; 257: 1955-1957.

9. Peng CY, Graves PR, Thoma RS, Wu Z, Shaw AS, Piwnica-Worms H. Mitotic and G2 checkpoint control: regulation of 14-3-3 protein binding by phosphorylation of Cdc25C on serine-216. Science 1997; 277: 1501-1505.

10. Robertson JD, Orrenius S. Molecular mechanisms of apoptosis induced by cytotoxic chemicals. Crit Rev Toxicol 2000; 30: 609-627.

11. Liu B, Cheng Y, Bian HJ, Bao JK. Molecular mechanisms of Polygonatum cyrtonema lectin-induced apoptosis and autophagy in cancer cells. Autophagy 2009; 5: 253-255.

12. Lawen A. Apoptosis-an introduction. Bioessays 2003; 25: 888-896.

13. Antonsson B, Martinou JC. The Bcl-2 protein family. Exp Cell Res 2000; 256: 50-57.

14. Thannickal VJ, Fanburg BL. Reactive oxygen species in cell signaling. Am J Physiol Lung Cell Mol Physiol 2000; 279: L1005-L1028.

15. Sauer $H$, Wartenberg $M$, Hescheler J. Reactive oxygen species as intracellular messengers during cell growth and differentiation. Cell Physiol Biochem 2001; 11: 173-186.

16. Crompton M. The mitochondrial permeability transition pore and its role in cell death. Biochem J 1999; 341: 233-249

17. Khosravi-Far R, Solski PA, Clark GJ, Kinch MS, Der CJ. Activation of Rac1, RhoA, and mitogen-activated protein kinases is required for Ras transformation. Mol Cell Biol 1995; 15: 6443-6453.

18. Bacus SS, Gudkov AV, Lowe M, Lyass L, Yung Y, Komarov AP et al. Taxol-induced apoptosis depends on MAP kinase pathways (ERK and p38) and is independent of p53. Oncogene 2001; 20: 147-155.

19. Johnson GL, Lapadat R. Mitogen-activated protein kinase pathways mediated by ERK, JNK, and p38 protein kinases. Science 2002; 298: 1911-1912.

20. Xia Z, Dickens M, Raingeaud J, Davis RJ, Greenberg ME. Opposing effects of ERK and JNK-p38 MAP kinases on apoptosis. Science 1995; 270: 1326-1331.

21. Sun H, Li X, Meng L, Cui C, Gao S, Li C et al. Asperolides A-C, tetranorlabdane diterpenoids from the marine alga-derived endophytic fungus Aspergillus wentii EN-48. J Nat Prod 2012; 75: 148-152.

22. Zhang Z, Miao L, Sun W, Jiao B, Wang B, Yao L et al. Wentilactone B from Aspergillus wentii induces apoptosis and inhibits proliferation and migration of human hepatoma SMMC-7721 cells. Biol Pharm Bull 2012; 35: 1964-1971.

23. Ming ZJ, Hu Y, Qiu YH, Cao L, Zhang XG. Synergistic effects of beta-aescin and 5-fluorouracil in human hepatocellular carcinoma SMMC-7721 cells. Phytomedicine 2010; 17: $575-580$.

24. Cao XW, Fu ZR, Ding GS. Effects of tacrolimus on proliferation, apoptosis, and fluorouracil sensitivity of liver cancer cell line of SMMC-7721. Hepatobiliary Pancreat Dis Int 2005; 4: 269-273.

25. Fleury C, Mignotte B, Vayssière JL. Mitochondrial reactive oxygen species in cell death signaling. Biochimie 2002; 84: 131-141.

26. Remacle-Bonnet MM, Garrouste FL, Heller S, Andre F, Marvaldi JL, Pommier GJ. Insulin-like growth factor-I protects colon cancer cells from death factor-induced apoptosis by potentiating tumor necrosis factor alphainduced mitogen-activated protein kinase and nuclear factor kappaB signaling pathways. Cancer Res 2000; 60: 2007-2017.

27. Miyoshi N, Uchida K, Osawa T, Nakamura Y. A link between benzyl isothiocyanate-induced cell cycle arrest and apoptosis: involvement of mitogen-activated protein kinases in the Bcl-2 phosphorylation. Cancer Res 2004; 64: 2134-2142. 
28. Post GR, Brown JH. G protein-coupled receptors and signaling pathways regulating growth responses. FASEB J 1996; 10: 741-749.

29. Auer KL, Contessa J, Brenz-Verca S, Pirola L, Rusconi S, Cooper G et al. The Ras/Rac1/ Cdc42/SEK/JNK/c-Jun cascade is a key pathway by which agonists stimulate DNA synthesis in primary cultures of rat hepatocytes. Mol Biol Cell 1998; 9: 561-573.

30. Lee SJ, Cho YH, Park K, Kim EJ, Jung KH, Park SS et al. Magnolol elicits activation of the extracellular signal-regulated kinase pathway by inducing p27KIP1-mediated G2/M-phase cell cycle arrest in human urinary bladder cancer 5637 cells. Biochem Pharmacol 2008; 75: 2289-2300.

31. Díez D, Sánchez-Jiménez F, Ranea JA. Evolutionary expansion of the Ras switch regulatory module in eukaryotes. Nucleic Acids Res 2011; 39: 5526-5537.

32. Shields JM, Pruitt K, McFall A, Shaub A, Der CJ. Understanding Ras: 'it ain't over 'til it's over'. Trends Cell Biol 2000; 10: 147-154.

33. Perdiguero E, Nebreda AR. Regulation of Cdc25C activity during the meiotic G2/M transition. Cell Cycle 2004; 3: 733-737.

34. Gabrielli BG, Clark JM, McCormack AK, Ellem KA. Hyperphosphorylation of the N-terminal domain of $\mathrm{Cdc} 25$ regulates activity toward cyclin B1/Cdc2 but not cyclin A/Cdk2. J Biol Chem 1997; 272: 28607-28614.

35. Taylor WR, Stark GR. Regulation of the G2/M transition by p53. Oncogene 2001; 20: 1803-1815.

36. Vousden KH, Lane DP. p53 in health and disease. Nat Rev Mol Cell Biol 2007; 8: 275-283.

37. Li S, Dong P, Wang J, Zhang J, Gu J, Wu X et al. Icariin, a natural flavonol glycoside, induces apoptosis in human hepatoma SMMC-7721 cells via a ROS/JNK-dependent mitochondrial pathway. Cancer Lett 2010; 298: 222-230.

38. Sun SY, Hail N Jr, Lotan R. Apoptosis as a novel target for cancer chemoprevention. J Natl Cancer Inst 2004; 96: 662-672.

39. Hengartner MO. The biochemistry of apoptosis. Nature 2000; 407: 770-776.

40. Feng B, Guo YW, Huang CG, Li L, Chen RH, Jiao BH. 2'-epi-2'-O-Acetylthevetin B extracted from seeds of Cerbera manghas $L$. induces cell cycle arrest and apoptosis in human hepatocellular carcinoma HepG2 cells. Chem Biol Interact 2010; 183: 142-153.

41. Lin HH, Chen JH, Huang CC, Wang CJ. Apoptotic effect of 3,4-dihydroxybenzoic acid on human gastric carcinoma cells involving JNK/p38 MAPK signaling activation. Int J Cancer 2007; 120: 2306-2316.

42. Kallio A, Zheng A, Dahllund J, Heiskanen KM, Härkönen P. Role of mitochondria in tamoxifen-induced rapid death of MCF-7 breast cancer cells. Apoptosis 2005; 10: 1395-1410.
43. Kuo PL, Chen CY, Hsu YL. Isoobtusilactone A induces cell cycle arrest and apoptosis through reactive oxygen species/apoptosis signal-regulating kinase 1 signaling pathway in human breast cancer cells. Cancer Res 2007; 67: 7406-7420.

44. Xiao D, Herman-Antosiewicz A, Antosiewicz J, Xiao H, Brisson M, Lazo JS et al. Diallyl trisulfide-induced $\mathrm{G}(2)-\mathrm{M}$ phase cell cycle arrest in human prostate cancer cells is caused by reactive oxygen species-dependent destruction and hyperphosphorylation of Cdc $25 \mathrm{C}$. Oncogene 2005; 24: 6256-6268.

45. Santarpia L, Lippman SM, El-Naggar AK. Targeting the MAPK-RAS-RAF signaling pathway in cancer therapy. Expert Opin Ther Targets 2012; 16: 103-119.

46. Kurosu T, Takahashi Y, Fukuda T, Koyama T, Miki T, Miura O. p38 MAP kinase plays a role in $\mathrm{G} 2$ checkpoint activation and inhibits apoptosis of human B cell lymphoma cells treated with etoposide. Apoptosis 2005; 10: 1111-1120.

47. Shen HM, Liu ZG. JNK signaling pathway is a key modulator in cell death mediated by reactive oxygen and nitrogen species. Free Radic Biol Med 2006; 40: 928-939.

48. Okano J, Rustgi AK. Paclitaxel induces prolonged activation of the Ras/MEK/ERK pathway independently of activating the programmed cell death machinery. J Biol Chem 2001; 276: 19555-19564.

49. Shimizu M, Imai K, Takai K, Moriwaki H. Role of acyclic retinoid in the chemoprevention of hepatocellular carcinoma: basic aspects, clinical applications, and future prospects. Curr Cancer Drug Targets 2012; 12: 1119-1128.

50. Lu B, Hu M, Liu K, Peng J. Cytotoxicity of berberine on human cervical carcinoma HeLa cells through mitochondria, death receptor and MAPK pathways, and in-silico drug-target prediction. Toxicol In Vitro 2010; 24: 1482-1490.

51. Armstrong JS, Steinauer KK, Hornung B, Irish JM, Lecane P, Birrell GW et al. Role of glutathione depletion and reactive oxygen species generation in apoptotic signaling in a human B lymphoma cell line. Cell Death Differ 2002; 9: 252-263.

52. Yue QX, Cao ZW, Guan SH, Liu XH, Tao L, Wu WY et al. Proteomics characterization of the cytotoxicity mechanism of ganoderic acid $D$ and computer-automated estimation of the possible drug target network. Mol Cell Proteomics 2008; 7: 949-961.

(c) (i) $\odot$ Cell Death and Disease is an open-access journal published by Nature Publishing Group. This work is licensed under a Creative Commons Attribution-NonCommercialNoDerivs 3.0 Unported License. To view a copy of this license, visit http://creativecommons.org/licenses/by-nc-nd/3.0/

\section{Supplementary Information accompanies this paper on Cell Death and Disease website (http://www.nature.com/cddis)}

